\title{
Critical role of inducible nitric oxide synthase in degeneration of retinal capillaries in mice with streptozotocin-induced diabetes
}

\author{
L. Zheng $\cdot$ Y. Du $\cdot$ C. Miller $\cdot$ R. A. Gubitosi-Klug $\cdot$ \\ T. S. Kern • S. Ball • B. A. Berkowitz
}

Received: 21 March 2007 / Accepted: 30 April 2007 / Published online: 22 June 2007

(C) Springer-Verlag 2007

\begin{abstract}
Aims/hypothesis Diabetes results in the upregulation of the production of several components of the inflammatory response in the retina, including inducible nitric oxide synthase (iNOS). The aim of this study was to investigate
\end{abstract}

L. Zheng $(\bowtie) \cdot$ Y. Du $\cdot$ C. Miller $\cdot$ T. S. Kern $(\bowtie)$

Department of Medicine, 448B Biomedical Research Building,

Case Western Reserve University,

10900 Euclid Avenue,

Cleveland, OH 44106, USA

e-mail: ling.zheng@case.edu

e-mail: tsk@case.edu

\section{T. S. Kern}

Department of Ophthalmology, 434 Biomedical Research

Building, Case Western Reserve University,

10900 Euclid Avenue,

Cleveland, OH 44106, USA

\section{Miller}

Alcon Research,

Fort Worth, TX, USA

R. A. Gubitosi-Klug

Department of Pediatrics, Rainbow Babies and Children's

Hospital, Case Western Reserve University,

Cleveland, OH, USA

T. S. Kern $\cdot$ S. Ball

Cleveland VAMC Research Service 151,

Cleveland, $\mathrm{OH}$, USA

\section{B. A. Berkowitz}

Department of Anatomy and Cell Biology,

Wayne State University,

Detroit, MI, USA

\section{B. A. Berkowitz}

Department of Ophthalmology, Wayne State University,

Detroit, MI, USA the role of iNOS in the pathogenesis of the early stages of diabetic retinopathy using iNOS-deficient mice $\left(\mathrm{iNos}^{-1}\right)$. Materials and methods $i_{N o s}{ }^{-1}$ mice and wild-type (WT; C57BL/6J) mice were made diabetic with streptozotocin or kept as non-diabetic controls. Mice were killed at different time points after the induction of diabetes for assessment of vascular histopathology, cell loss in the ganglion cell layer (GCL), retinal thickness, and biochemical and physiological abnormalities.

Results The concentrations of nitric oxide, nitration of proteins, poly(ADP-ribose) (PAR)-modified proteins, endothelial nitric oxide synthase, prostaglandin $\mathrm{E}_{2}$, superoxide and leucostasis were significantly $(p<0.05)$ increased in retinas of WT mice diabetic for 2 months compared with nondiabetic WT mice. All of these abnormalities except PARmodified proteins in retinas were inhibited $(p<0.05)$ in diabetic $\mathrm{iNos}^{-/}$mice. The number of acellular capillaries and pericyte ghosts was significantly increased in retinas from WT mice diabetic for 9 months compared with nondiabetic WT controls, these increases being significantly inhibited in diabetic $i \mathrm{Nos}^{-1-}$ mice ( $p<0.05$ for all). Retinas from WT diabetic mice were significantly thinner than those from their non-diabetic controls, whereas diabetic $i \mathrm{Nos}^{-1-}$ mice were protected from this abnormality. We found no evidence of cell loss in the GCL of diabetic WT or $i \mathrm{Nos}^{-/-}$mice. Deletion of iNos had no beneficial effect on diabetes-induced abnormalities on the electroretinogram. Conclusions/interpretation We demonstrate that the inflammatory enzyme iNOS plays an important role in the pathogenesis of vascular lesions characteristic of the early stages of diabetic retinopathy in mice.

Keywords Capillary degeneration - Diabetic retinopathy . Inducible nitric oxide synthase - Inflammation · Nitric oxide · PAR activation 


$\begin{array}{ll}\text { Abbreviations } \\ \text { eNOS } & \text { endothelial nitric oxide synthase } \\ \text { ERG } & \text { electroretinogram } \\ \text { GCL } & \text { ganglion cell layer } \\ \text { iNOS } & \text { inducible nitric oxide synthase } \\ \text { IPL } & \text { inner plexiform layer } \\ \text { NF-kB } & \text { nuclear factor kappa B } \\ \text { NOS } & \text { nitric oxide synthase } \\ \text { nNOS } & \text { neuronal nitric oxide synthase } \\ \text { OPL } & \text { outer plexiform layer } \\ \text { PAR } & \text { poly(ADP-ribose) } \\ \text { PARP } & \text { poly(ADP-ribose) polymerase } \\ \text { PASH } & \text { periodic acid-Schiff and haematoxylin } \\ \text { PGE } & \text { prostaglandin } E_{2} \\ \text { WT } & \text { wild-type }\end{array}$

\section{Introduction}

Excessive production of nitric oxide is thought to play a role in inflammatory diseases (reviewed in [1]). Nitric oxide is generated from L-arginine by the catalytic reaction of different isoforms of nitric oxide synthase (NOS), including neuronal NOS (nNOS), endothelial NOS (eNOS) and inducible NOS (iNOS). Normal functions of nitric oxide include regulation of vessel tone, but it can also react with superoxide anion to form peroxynitrite, which can damage proteins, lipid and DNA. It is believed that the relatively smaller amount of nitric oxide generated by eNOS and nNOS are involved in physiological functions, whereas the comparatively larger amount of nitric oxide generated by iNOS is involved in inflammatory diseases $[1,2]$.

Diabetes results in upregulation of a number of components of the inflammatory response in the retina. Upregulation of iNOS level has been found in retinas of experimental diabetic rodents and human patients in most studies [3-6]. The significance of this enzyme in the development of diabetic retinopathy has not yet been defined, but increased production of nitric oxide is at least closely associated with the development of retinopathy. A possible role of iNOS in this is suggested by studies of aminoguanidine. Aminoguanidine is a relatively selective inhibitor of iNOS [7] and has been found to inhibit the diabetes-induced increase in iNOS levels and nitric oxide production in retina [4]. Importantly, aminoguanidine has also been found to inhibit development of the microvascular lesions of diabetic retinopathy in diabetic dogs $[8]$, rats $[9,10]$ and mice (T. S. Kern, unpublished data). However, results from these aminoguanidine studies did not suffice to prove that iNOS plays a critical role in diabetes-induced retinal pathology, since aminoguanidine has also been shown to inhibit dicarbonylmediated cross-linking and protein modification [11] and can even inhibit eNOS level under some circumstances [12]. Thus, to investigate the role of iNOS in the pathogenesis of diabetic retinopathy, we studied diabetic mice that are deficient in $i N o s$.

\section{Materials and methods}

Streptozotocin-induced model of diabetes Breeder pairs of $i \mathrm{Nos}^{-1-}$ mice along with wild-type mice (WT; C57BL/6J) were purchased from Jackson laboratories (Bar Harbor, ME, USA). Offspring of $i \mathrm{Nos}^{-/-}$and WT mice were housed in ventilated microisolator cages. All experiments followed the guidelines set forth by the Association for Research in Vision and Ophthalmology Resolution on Treatment of Animals in Research. Insulin-deficient diabetes was induced in fasted mice by intraperitioneal injections of streptozotocin (55 mg/kg body weight) on 3-5 consecutive days. Insulin was given as needed to maintain body weight and allow a slow increase in body weight while allowing hyperglycaemia, polyuria and hyperphagia (0-0.2 U every 2-3 days). Hyperglycaemia was quantified every $2-3$ months by measuring total glycated haemoglobin levels (Variant II total GHb Program; BioRad, Hercules, CA, USA) and by measuring blood glucose concentrations. Diabetic and agematched non-diabetic controls were killed at 6 and 9 months of diabetes for assessment of vascular histopathology and at 2-4 months of diabetes for assessment of cell loss in the ganglion cell layer (GCL), as well as biochemical and physiological abnormalities.

Measurement of nitric oxide Nitric oxide was determined in retina by measuring the stable metabolites of nitric oxide (nitrate+nitrite) using a fluorimetric assay kit (Cayman Chemical, Ann Arbor, MI, USA) as reported previously [4, 13, 14].

Estimation of superoxide anion The assay was performed as previously reported [15]. Briefly, freshly isolated retinas from mice were first equilibrated in Krebs-HEPES buffer in the dark at $37^{\circ} \mathrm{C}$ in $95 \% \mathrm{O}_{2} / 5 \% \mathrm{CO}_{2}$ for $30 \mathrm{~min}$. After incubation, $0.5 \mathrm{mmol} / 1$ lucigenin was added and luminescence was detected. Generation of luminescence can be inhibited with Tiron, a cell membrane permeable scavenger of superoxide anion, suggesting the reaction provides a reasonable estimate of superoxide production.

Western blot analysis Rat retinas were isolated and sonicated. Total amount of protein was determined by a protein assay (BioRad). Proteins were separated by SDS-PAGE and antibodies for nitrotyrosine (Upstate Biotechnology, Lake Placid, NY, USA), eNOS (BD Biosciences, San Jose, CA, USA) and poly(ADP-ribose) (PAR) (Axxora LLC, San Diego, CA, USA) were applied. After extensive washing, 
Table 1 Physiological parameters of experimental groups

${ }^{*} p<0.05$ vs non-diabetic WT and $\mathrm{iNos}^{-1-}$

\begin{tabular}{lllll}
\hline Group & $\begin{array}{l}\text { Duration } \\
\text { (months) }\end{array}$ & $\begin{array}{l}\text { Total GHb } \\
(\%)\end{array}$ & $\begin{array}{l}\text { Blood glucose } \\
(\mathrm{mmol} / \mathrm{l})\end{array}$ & $\begin{array}{l}\text { Body weight } \\
(\mathrm{g})\end{array}$ \\
\hline WT non-diabetic & 9 & $4.1 \pm 0.3$ & $8.6 \pm 1.1$ & $43 \pm 6$ \\
iNos $^{-/-}$non-diabetic & 9 & $4.3 \pm 0.3$ & $8.6 \pm 3.2$ & $44 \pm 6$ \\
WT diabetic $^{-1}$ diabetic & 9 & $13.7 \pm 1.5^{*}$ & $21.7 \pm 3.1^{*}$ & $24 \pm 3^{*}$ \\
& 9 & $13.8 \pm 2.4^{*}$ & $20.4 \pm 2.4^{*}$ & $23 \pm 3^{*}$ \\
\hline
\end{tabular}

protein bands detected by the antibody were visualised by enhanced chemiluminescence (Santa Cruz Biotechnology, Santa Cruz, CA, USA). Membrane was then stripped and re-probed with antibody against $\beta$-actin (Sigma, St Louis, MO, USA) to confirm equal protein loading. The films were subsequently scanned and band intensity was quantitated using a software package (Quantity One 1-D Analysis; BioRad).

Measurement of prostaglandin $E_{2}$ Prostaglandin $\mathrm{E}_{2}\left(\mathrm{PGE}_{2}\right)$ in homogenised samples of retina was measured by ELISA using a commercial kit (Cayman Chemical) as previously reported [13]. All assays were done in duplicate and at two different dilutions of homogenate. The amount of $\mathrm{PGE}_{2}$ in the retina was normalised by the total amount of protein in the corresponding retinal extracts and the $\mathrm{PGE}_{2}$ content of each sample calculated as $\mathrm{pg} / \mathrm{mg}$ protein.

Quantitative measurement of leucostasis At 3 months of diabetes, blood was removed from the vasculature of anaesthetised animals (ketamine $100 \mathrm{mg} / \mathrm{ml}$ :xylazine $100 \mathrm{mg} / \mathrm{ml}=$ $5: 1)$ by complete perfusion with PBS via a heart catheter. Animals were then perfused with fluorescein-coupled concanavalin A lectin $(20 \mu \mathrm{g} / \mathrm{ml}$ in PBS; Vector Laboratories, Burlingame, CA, USA) as described previously [16, 17]. Flat-mounted retinas were imaged via fluorescence microscopy and the number of leucocytes adherent to the vascular wall was counted.
Quantification of vascular histopathology The retinal vasculature was isolated by the trypsin digest method as described by us previously [8, 17]. Briefly, freshly isolated eyes were fixed with buffered formalin (4\% [wt/vol.] formaldehyde, $0.075 \mathrm{~mol} / 1$ sodium phosphate buffer). Retinas were isolated, washed in water overnight and then incubated with 3\% Difco crude typsin (BD, Sparks, MD, USA) at $37^{\circ} \mathrm{C}$ for $1 \mathrm{~h}$. Non-vascular cells were gently brushed away from the vasculature, the isolated vasculature was mounted on glass slides, air-dried and stained with periodic acid-Schiff and haematoxylin (PASH). Acellular capillaries were quantified in six to eight field areas in the mid-retina (×400 magnification) in a masked manner. Acellular capillaries were identified as capillary-sized vessel tubes having no nuclei anywhere along their length and reported per square millimetre of retinal area. Tubes having a diameter $<30 \%$ of the diameter of adjacent capillaries were identified as strands and not counted as acellular capillaries. Pericyte ghosts were estimated from the prevalence of spaces in the capillary basement membranes from which pericytes had disappeared. At least 1,000 capillary cells in seven field areas in the mid-retina ( $\times 400$ magnification) were evaluated and the number of pericyte ghosts reported per 1,000 capillary cells.

Cell count and retinal thickness The enucleated eyes were fixed in buffered formalin, embedded in paraffin and sectioned. To control for artefacts resulting from the a

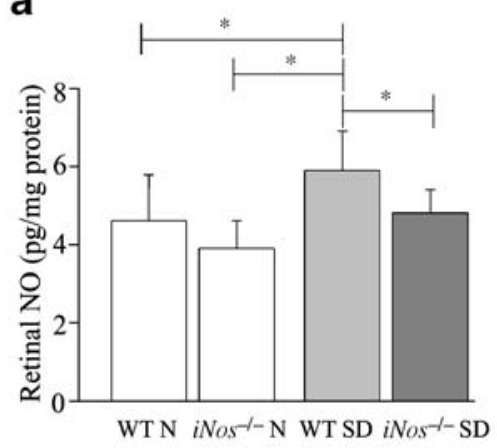

b

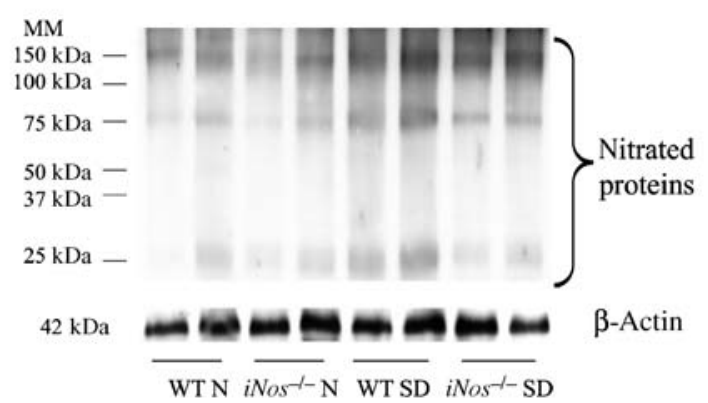

C

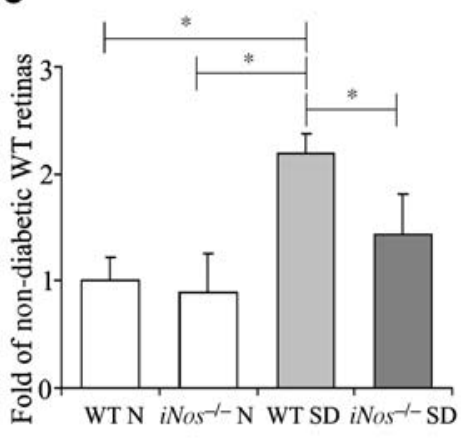

Fig. 1 Genetic deletion of iNos in diabetic mice inhibits diabetesinduced production of nitric oxide and protein nitration. a Measurement of total nitric oxide (nitrite and nitrate) in the retinas. b Western blots of nitrated proteins in retina ( $n=7-8$ from each group). c Quantification of extent of nitration of retinal proteins. Intensity is reported relative to $\beta$-actin in same sample and normalised to nondiabetic controls, set at $1 .{ }^{*} p<0.05$. $M M$ molecular mass, $W T N$ nondiabetic wild-type mice, $\mathrm{iNos}^{-1-} \mathrm{N}$ non-diabetic $\mathrm{iNos}^{-1-}$ mice, WT SD streptozotocin diabetic wild-type mice, $i \mathrm{Nos}^{-/-} \mathrm{SD}$ diabetic $\mathrm{iNos}^{-1-}$ mice 
sectioning angle, all sections were cut tangentially through pupil and optic nerve, thus ensuring an essentially tangential cut through the centre of the eye. The cross-sections were stained with PASH for retinal morphology examination. The nuclei in the GCL (not including nuclei of blood vessels in that layer) were counted and the thickness of various retinal layers measured in six locations in the retina (three locations on each side of the optic nerve) under $\times 400$ magnification with Image-Pro 4.0 software (Media Cybernetics, Bethesda, MD, USA).

Electroretinogram Measurements were made as described previously [18] with three to ten animals per group. Mice were adapted to the dark overnight, anaesthetised and placed on a heating pad during the recording session. Pupils were dilated with $1 \%(\mathrm{wt} / \mathrm{vol}$.) tropicamide, $1 \%(\mathrm{wt} / \mathrm{vol}$.) cyclopentalate hydrochloride and $2.5 \%$ (wt/vol.) phenylephrine hydrochloride. Recordings were made using a stainless steel wire loop that contacted the corneal surface through a thin layer of $1 \%(\mathrm{wt} / \mathrm{vol}$.) methylcellulose. Needle electrodes placed in the tail and cheek served as ground and reference electrodes, respectively. Responses were amplified $(1-1,000 \mathrm{~Hz})$, averaged and stored on an UTAS signal averaging system (LKC Technologies, Gaithersbug, MD, USA). A darkness-adapted intensity-response series was a
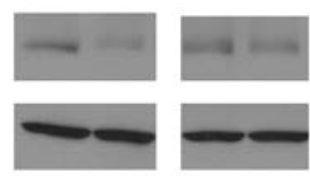

WT N

iNos $^{-1-} \mathrm{N}$
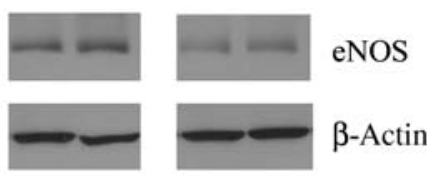

WT SD

iNos $^{-1-}$ SD b

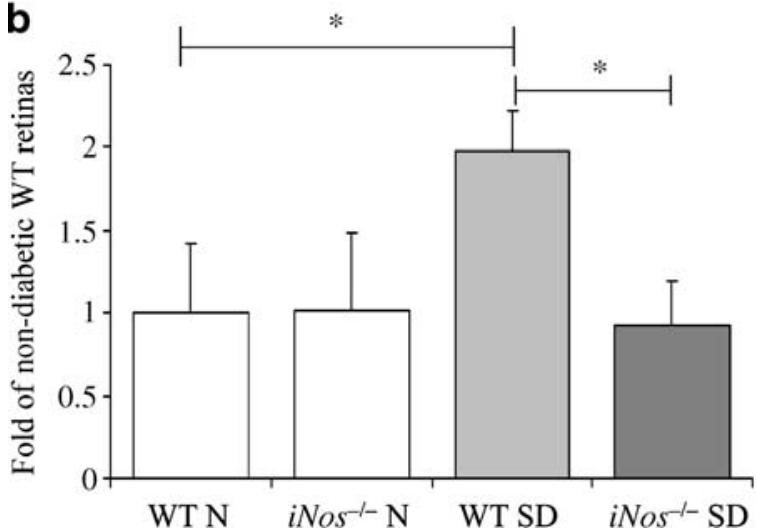

Fig. 2 eNOS expression is elevated in retinas of diabetic wild-type mice, but not in retinas of diabetic $i \mathrm{Nos}^{-1-}$ mice. a Representative results of western blots of eNOS expression in retinas. b Quantitative summary of eNOS expression. Intensity is reported relative to $\beta$-actin in same sample and normalised to non-diabetic controls, set at 1. $n=$ 4-5 from each group; ${ }^{*} p<0.05$. WT $N$ non-diabetic wild-type mice; $\mathrm{iNos}^{-1-} \mathrm{N}$ non-diabetic $\mathrm{iNos}^{-1-}$ mice, WT SD streptozotocin diabetic wild-type mice; $i \mathrm{Nos}^{-/-} \mathrm{SD}$ diabetic $\mathrm{iNos}^{-/-}$mice recorded using a series of Ganzfeld flashes with intensities ranging from -4.2 to $0.5 \log \mathrm{cd} \mathrm{s} / \mathrm{m}^{-2}$. Cone electroretinograms (ERGs) were obtained to stimuli after $7 \mathrm{~min}$ light adaptation in which the animals were exposed to a steady rod desensitising background light of $0.8 \log \mathrm{cd} / \mathrm{m}^{2}$ presented in the Ganzfeld bowl. Cone responses were elicited to a series of flash intensities $\left(-0.22\right.$ to $\left.0.52 \log \mathrm{cd} \mathrm{s} / \mathrm{m}^{-2}\right)$. For each intensity, the average response to 25 flashes was calculated. The amplitude and latency of the ERG a- and b-wave were measured conventionally. For the a-wave, amplitude was measured from the pre-stimulus baseline to the trough. For the b-wave, amplitude was measured from the negative trough of the a-wave to b-wave peak. Latency or time-to-peak, was measured from stimulus onset to the awave trough and $b$-wave peak. Summed oscillatory potential values were calculated for as reported previously [19].

Statistical analysis All results are expressed as the mean \pm SD. ERG results across different light intensities were analysed by repeated measures ANOVA and oscillatory potential was analysed by ANOVA followed by the Fischer post hoc test. Other data were analysed by the nonparametric KruskalWallis test followed by the Mann-Whitney $U$ test. Differences were considered statistically significant when the $p$ values were less than 0.05 .

a
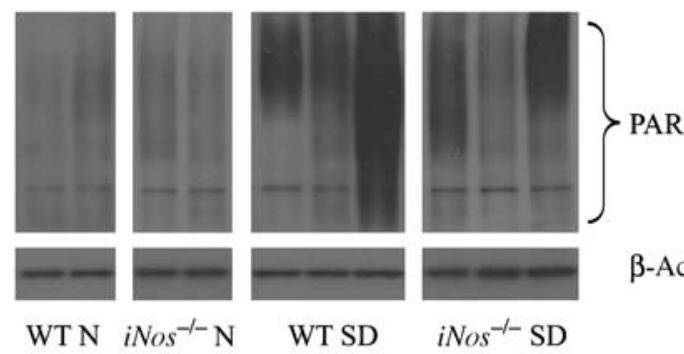

WT SD

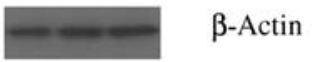

b

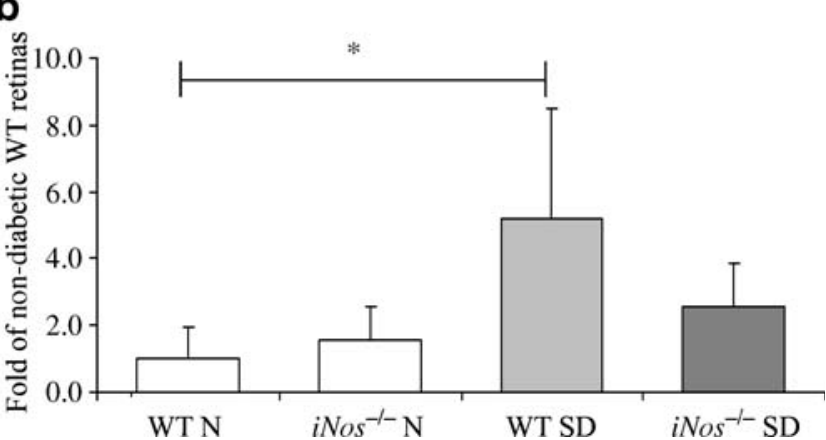

Fig. 3 PARP activity in the retinas of diabetic mice. a Representative results of western blots of PAR-modified proteins in retinas. b Quantitative summary of PAR western blots. Expression is reported relative to $\beta$-actin in same sample and normalised to non-diabetic controls, set at 1 . $n=4-5$ from each group; ${ }^{*} p<0.05$. WT $N$ nondiabetic wild-type mice; $\mathrm{iNos}^{-/-} \mathrm{N}$ non-diabetic $\mathrm{iNos}^{-1-}$ mice, WT SD streptozotocin diabetic wild-type mice, $i \mathrm{Nos}^{-1-} \mathrm{SD}$ diabetic $\mathrm{iNos}^{-1}$ mice 


\section{Results}

Total GHb and blood glucose values in diabetic $i \mathrm{Nos}^{-/-}$ mice were not significantly different from those in diabetic WT mice and were significantly higher than corresponding values in non-diabetic mice (Table 1). Body weights of both groups of diabetic mice remained significantly lower than those of non-diabetic mice. All mice lacking iNos appeared healthy.

Previous work has demonstrated that diabetes can induce excessive nitric oxide production in retinas of diabetic rats and mice $[3,4,20]$. To investigate whether iNOS contributed to this nitric oxide production, we measured nitric oxide production (indicated by total of nitrite and nitrate, the stable metabolites of nitric oxide) in retinas of WT and $i \mathrm{Nos}^{-1-}$ mice that had diabetes for 3 months, as well as in retinas of their age-matched non-diabetic controls. As shown in Fig. 1a, diabetes in WT mice caused a modest (1.3-fold), but significant elevation of nitric oxide in retinas $(p<0.05$ compared with non-diabetic WT controls); however, no such elevation was seen in the retinas of diabetic $i \mathrm{Nos}^{-/-}$mice $(p<0.05$ compared with diabetic WT) (Fig. 1a). Consistent with this observation, nitration of retinal proteins was increased in WT diabetic mice compared with nondiabetic WT mice (especially in proteins with molecular weights between 70 and $75 \mathrm{kDa}$, and about $25 \mathrm{kDa}$ ), while diabetic $\mathrm{iNos}^{-1-}$ mice showed less protein nitration than diabetic WT mice (Fig. 1b). Intensity of all bands of nitrated proteins within the molecular weight range is summarised in Fig. 1c.

The eNOS level has also been reported to be elevated in the retinas of diabetic rats. It has been suggested that eNOS might play a role in the development of diabetes-induced leucostasis and/or diabetic retinopathy [21, 22]. In WT mice, diabetes of 2 months duration induced an approximately twofold increase in eNOS production in retinas $(p<0.05)$ (Fig. 2), whereas eNOS production in $\mathrm{iNos}^{-/-}$ mice was not altered by diabetes.

Excessive production of nitric oxide via iNOS has been shown by many investigators to cause DNA breaks and subsequent activation of poly(ADP-ribose) polymerase (PARP) [23], suggesting that iNOS is upstream of PARP in those acute inflammatory models. Inasmuch as we previously have shown that PARP plays a critical role in the degeneration of retinal capillaries in diabetes [17], we sought to determine whether or not iNOS might be the cause of that PARP activation. In WT mice, diabetes caused an increase in the level of PARP activity (estimated from the amount of PAR-modified retinal proteins) $(p<0.05)$ (Fig. 3$)$, but there was considerable variability among animals. Diabetic mice lacking iNos tended to have less PAR-modified retinal proteins, but the results did not achieve statistical significance.

The number of degenerate acellular capillaries, an important histological marker of early diabetic retinopathy, was significantly increased in retinas from WT mice that had been diabetic for 9 months (but not 6 months; not shown) compared with age-matched control mice $(p<0.01)$ (Fig. 4a). The diabetes-induced increase in these degenerate retinal capillaries was significantly inhibited in mice lacking iNos $(p<0.01)$. The number of pericyte ghosts, another histological marker of retinopathy, was also increased significantly in retinal vessels from diabetic WT mice compared with non-diabetic WT mice, an increase significantly inhibited in diabetic $i \mathrm{Nos}^{-/-}$mice $(p<0.05$ for both) (Fig. 4b). There was no statistically significant difference in the number of acellular capillaries or pericyte ghosts per retina between non-diabetic WT and nondiabetic $i \mathrm{Nos}^{-1-}$ mice.

Retinas from WT mice that had been diabetic for 3 to 4 months were significantly thinner than those from their non-diabetic controls (Table 2). Diabetes-induced retinal thinning achieved statistical significance in GCL, inner plexiform layer (IPL) and outer plexiform layer (OPL). However, there was no evidence of retinal thinning in diabetic $i \mathrm{Nos}^{-1-}$ mice. Neither diabetic WT nor $i \mathrm{Nos}^{-1-}$ mice showed evidence of cell loss in the GCL compared with their nondiabetic controls at this duration of study.

Prior studies of retinal cells exposed to elevated glucose have demonstrated: (1) that nitric oxide (especially that from iNOS) regulates production of $\mathrm{PGE}_{2}$, the inflamma-
Fig. 4 Genetic deletion of $i$ Nos inhibits diabetes-induced capillary degeneration in retinas of mice diabetic for 9 months. Acellular capillaries (a) and pericyte ghosts (b) were counted on the isolated retinal vessels. $n$ $=10,7,6,18$ from left to right (a) and 6, 9, 6, 7 from left to right $(\mathbf{b}) ;{ }^{*} p<0.05$. WT $N$ nondiabetic wild-type mice, $i \mathrm{Nos}^{-/}$ $N$ non-diabetic $i \mathrm{Nos}^{-/-}$mice, $W T$ $S D$ streptozotocin diabetic wildtype mice, $\mathrm{iNos}^{-/-} \mathrm{SD}$ diabetic $\mathrm{iNos}^{-/-}$mice
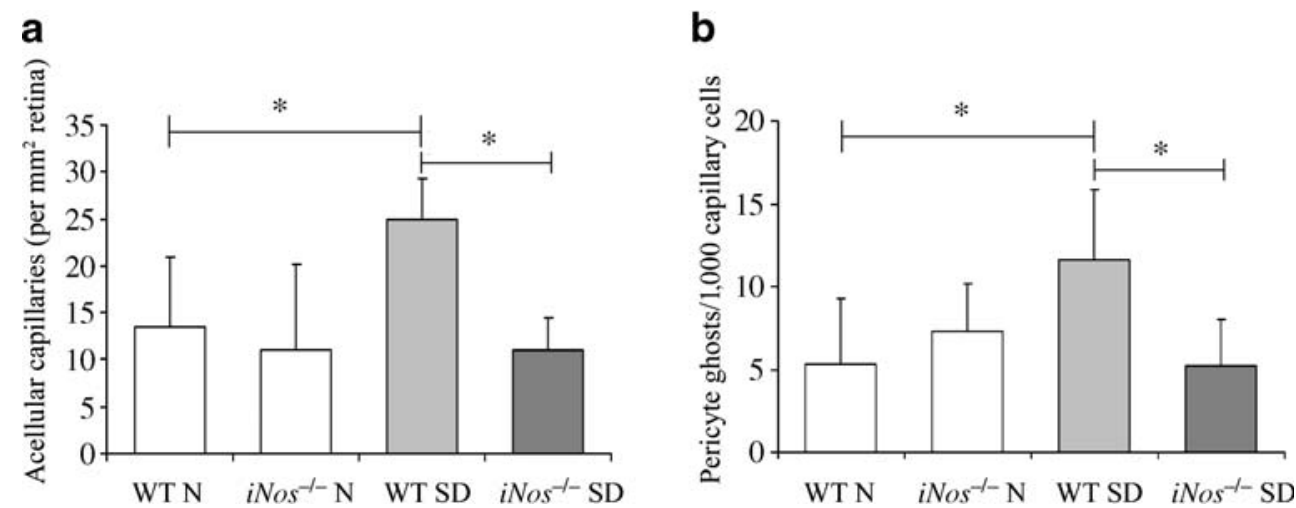
Table 2 Retinal thickness and number of cells in GCL in different experimental groups

\begin{tabular}{|c|c|c|c|c|c|c|c|}
\hline \multirow[t]{2}{*}{ Group $(n)$} & \multirow[t]{2}{*}{ Cells in $\mathrm{GCL}^{\mathrm{a}}$} & \multicolumn{6}{|c|}{ Retinal thickness $(\mu \mathrm{m})$} \\
\hline & & GCL & IPL & INL & OPL & ONL & Whole retina \\
\hline WT non-diabetic (9) & $12.3 \pm 1.6$ & $18.2 \pm 2.0$ & $47.9 \pm 3.9$ & $37.7 \pm 2.8$ & $13.3 \pm 1.6$ & $59.0 \pm 4.0$ & $176.0 \pm 12.3$ \\
\hline$i \mathrm{Nos}^{-/-}$non-diabetic (5) & $13.4 \pm 2.8$ & $17.4 \pm 2.5$ & $46.3 \pm 6.5$ & $35.2 \pm 4.5$ & $12.5 \pm 1.6$ & $55.6 \pm 3.6$ & $167.0 \pm 17.8$ \\
\hline WT diabetic (6) & $13.0 \pm 1.6$ & $14.7 \pm 0.7 *$ & $42.9 \pm 3.3^{*}$ & $34.9 \pm 3.0$ & $11.5 \pm 0.7 *$ & $55.4 \pm 3.3$ & $159.4 \pm 9.7 *$ \\
\hline$i N o s^{-1-}$ diabetic (4) & $13.5 \pm 1.4$ & $16.3 \pm 1.8$ & $46.0 \pm 4.4$ & $38.4 \pm 4.1$ & $12.5 \pm 1.8$ & $59.4 \pm 3.6$ & $172.5 \pm 14.7$ \\
\hline
\end{tabular}

${ }^{*} p<0.05$ vs non-diabetic WT

${ }^{\mathrm{a}}$ Per $100 \mu \mathrm{m}$ (length) of retina

tory prostaglandin generated by cyclooxygenases [13]; and (2) that iNOS contributes to superoxide generation in macrophages [24]. Retinas from diabetic WT mice produced significantly more $\mathrm{PGE}_{2}$ (Fig. 5) and superoxide (Fig. 6) than did retinas from non-diabetic WT animals $(p<0.05$ for both), while retinas from diabetic $i \mathrm{Nos}^{-/-}$mice produced significantly less of both than did those from diabetic WT mice ( $p<0.05$ for both).

A diabetes-induced increase in leucostasis (leucocytes adhering to the luminal wall of the vasculature) has been postulated to contribute to endothelial cell death or dysfunction in the retina [25]. A significant increase in leucostasis was demonstrated in WT mice that had been diabetic for 3 months compared with their non-diabetic counterparts $(p<0.05)$ (Fig. 7). Leucostasis in diabetic $i \mathrm{Nos}^{-/-}$mice was significantly less pronounced than that in diabetic WT mice $(p<0.05)$, demonstrating that iNOS contributes to the observed increase in retinal leucostasis in diabetes.

Diabetes-induced loss of retinal function was studied by ERG in WT and $i \mathrm{Nos}^{-/-}$mice that had been diabetic for

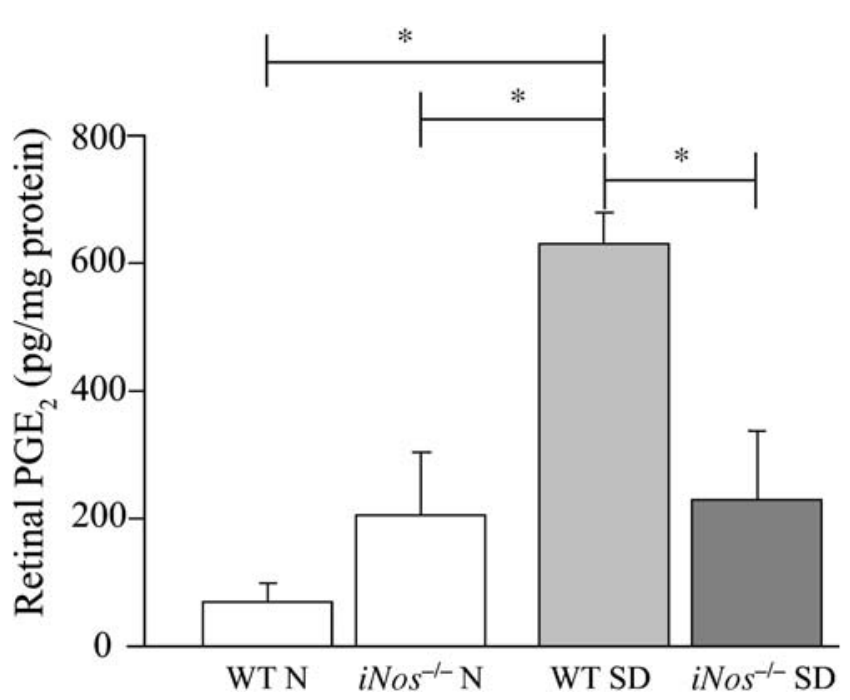

Fig. 5 Genetic deletion of iNos inhibits diabetes-induced overproduction of $\mathrm{PGE}_{2}$ in the retina. $n=7-8$ from each group; ${ }^{*} p<0.05$. $W T N$ non-diabetic wild-type mice, $i \mathrm{Nos}^{-1-} \mathrm{N}$ non-diabetic $i \mathrm{Nos}^{-1-}$ mice, WT SD streptozotocin diabetic wild-type mice, $i \mathrm{Nos}^{-1-} \mathrm{SD}$ diabetic $i \mathrm{Nos}^{-1-}$ mice
6 months. Compared with WT non-diabetic mice, the amplitudes of a-waves (dark-adapted) and b-waves of ERG (dark- and light-adapted) were reduced in diabetic WT mice $(p<0.001$ for all). Wave latencies were not significantly altered by diabetes in the WT animals. Darkadapted a-wave amplitude in both non-diabetic and diabetic $i \mathrm{Nos}^{-/-}$mice was significantly less pronounced than in the respective WT controls ( $p<0.05$; data not shown). The $i \mathrm{Nos}^{-/-}$diabetic mice differed from the non-diabetic $i \mathrm{Nos}^{-1-}$ controls only with respect to dark-adapted b-wave amplitude $(p<0.01)$ (Fig. 8), where the $i \mathrm{Nos}^{-/-}$diabetic mice had a lower amplitude than the WT non-diabetic and $i \mathrm{Nos}^{-/-}$ non-diabetic mice. Taken together, the data suggested that $i N o s$ deficiency did not prevent a diabetes-induced loss of dark-adapted amplitudes. Oscillatory potential was significantly different between: (1) WT diabetic and non-diabetic mice with respect to dark-adapted amplitude (587.5 \pm 195.8 vs $847.7 \pm 182.8 \mu \mathrm{V})$ and light-adapted latency $(208.1 \pm 26.0$ vs $170.2 \pm 28.5 \mathrm{~ms}$ ); and (2) $\mathrm{iNos}^{-/-}$diabetic and nondiabetic mice with respect to dark-adapted amplitude

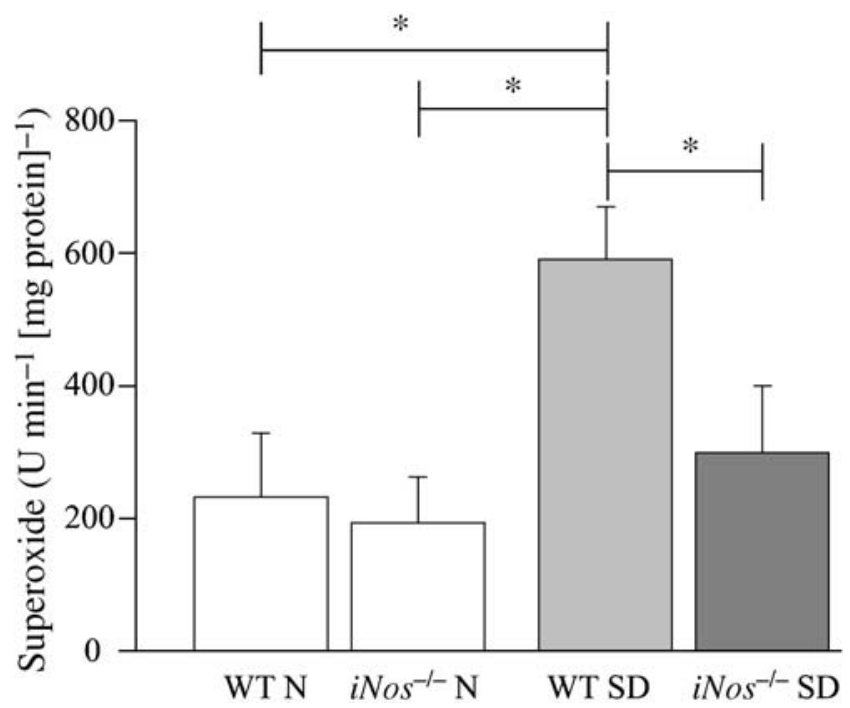

Fig. 6 Diabetes-induced over-production of superoxide in the retina does not occur in $i \mathrm{Nos}^{-1-}$ mice. $n=7-8$ from each group; ${ }^{*} p<0.05$. WT $N$ non-diabetic wild-type mice, $i \mathrm{Nos}^{-/-} \mathrm{N}$ non-diabetic $i \mathrm{Nos}^{-/-}$mice, WT SD streptozotocin diabetic wild-type mice, $\mathrm{iNos}^{-/-} \mathrm{SD}$ diabetic $i \mathrm{Nos}^{-1-}$ mice 


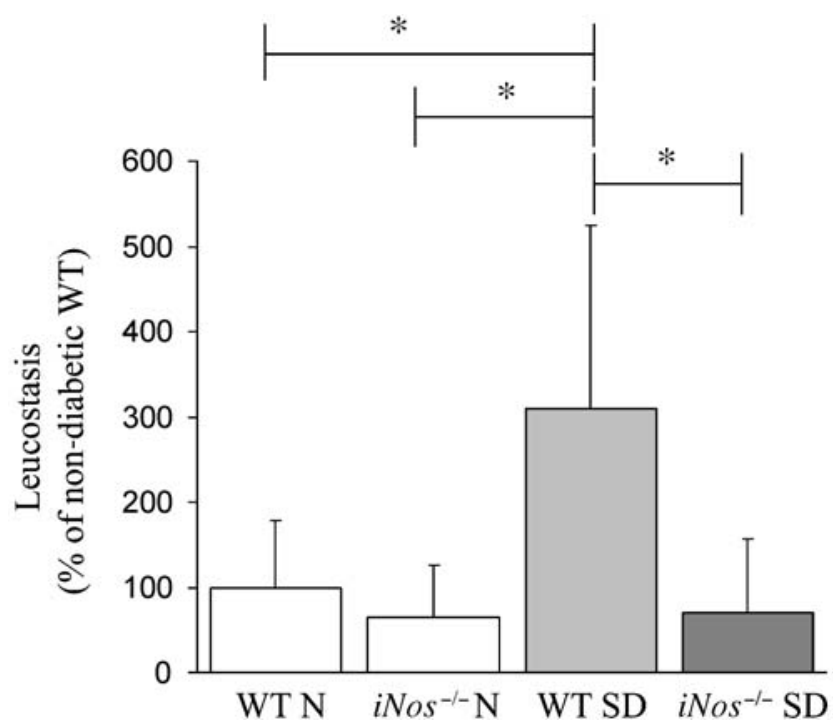

Fig. 7 Diabetes-induced leucostasis in retinal vessels is inhibited in $i \mathrm{Nos}^{-1-}$ mice. $n=7-8$ in each group; ${ }^{*} p<0.05$. WT $N$ non-diabetic wild-type mice, $i \mathrm{Nos}^{-/-} \mathrm{N}$ non-diabetic $\mathrm{iNos}^{-/-}$mice, WT SD streptozotocin diabetic wild-type mice, $\mathrm{iNos}^{-/} \mathrm{SD}$ diabetic $i \mathrm{Nos}^{-/-}$ mice

$(337.7 \pm 57.1$ vs $751.1 \pm 309.7 \mu \mathrm{V})$ and light-adapted amplitude $(195.5 \pm 23.9$ vs $166.1 \pm 32.2 \mu \mathrm{V})(p<0.05$ for all). No significant differences were observed between WT diabetic and $\mathrm{NOS}^{-/-}$diabetic mice.

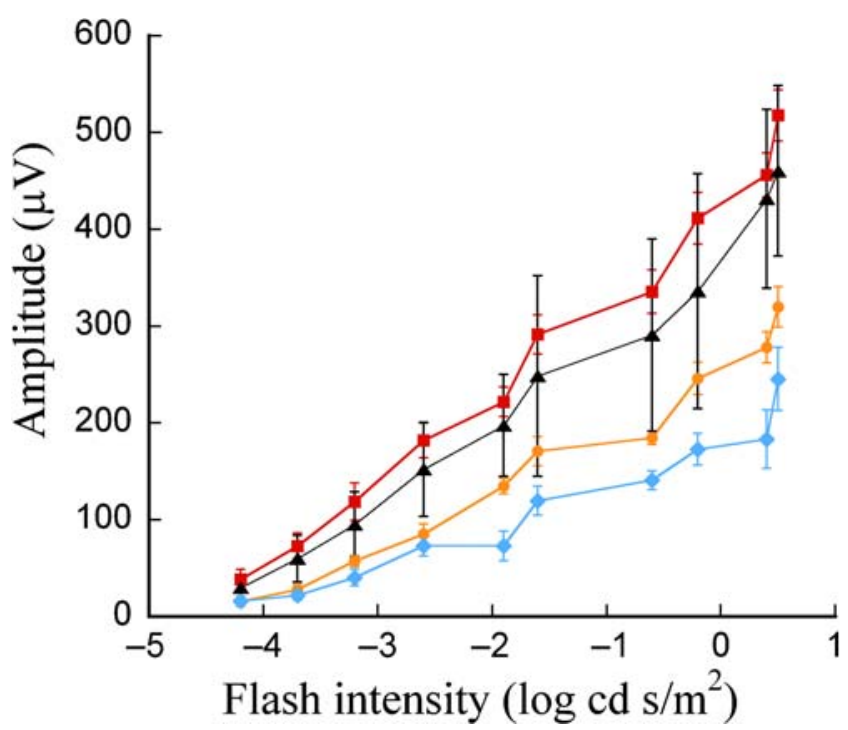

Fig. 8 Diabetes significantly decreased dark-adapted b-wave amplitude in WT mice, a defect also seen in diabetic mice lacking $i$ Nos. $n=$ 3-10 in each group. Red line, non-diabetic wild-type mice; black line, non-diabetic $i \mathrm{Nos}^{-/-}$mice; orange line, streptozotocin diabetic wildtype mice; black dotted line, diabetic $i \mathrm{Nos}^{-/}$mice. Error bars shown except when smaller than symbol

\section{Discussion}

The present studies use $i \mathrm{Nos}^{-/-}$mice to demonstrate that iNOS plays an important role in the pathogenesis of the vascular lesions of diabetic retinopathy. We found that mice lacking iNos were protected from the diabetes-induced production of nitric oxide, nitration of retinal proteins and, importantly, from the diabetes-induced degeneration of retinal capillaries. Previous research has demonstrated that inhibition of iNOS or iNos deficiency also inhibits development of early functional alterations in retinal oxygenation in diabetes [26, 27].

Retinal thinning has been found in the inner retina of diabetic rats and human patients [28]. In the present diabetic WT mice, we observed that thinning was due to thinning of the IPL and OPL. Since these plexiform layers represent interconnections between neurons, diabetes-induced reductions in synaptic connections [29] probably contribute to this thinning. Mice lacking iNos in our study did not show the diabetes-induced thinning of the retina, suggesting that the retinal thinning observed in our diabetic WT mice was due in part to iNOS or nitric oxide-mediated shrinkage or retraction of cell processes. Diabetes-induced retinal thinning has also been attributed, at least in part, to loss of retinal ganglion cells [28, 30-32]. However, our studies showed retinal thinning to occur although there was an apparent absence of cell loss in the GCL. The apparent lack of cell loss from the GCL of diabetic WT (C57BL/6J) mice is consistent with prior studies by us and others [33, 34], but is in contrast to another report using the same strain of mouse, where a $20 \%$ to $25 \%$ loss of cells in the GCL was observed after only 14 weeks of diabetes [35]. A 23\% loss of cell bodies in the GCL from another mouse strain (Ins2 ${ }^{\text {Akita }}$ mice) has been detected at 22 weeks of diabetes [36].

Diabetes-induced alterations in retinal thickness and structure might be expected to result in altered retinal function. Diabetes resulted in reduction of the ERG amplitudes of a- and b-waves in WT mice, but the absence of $i N O S$ did not prevent diabetes-induced retinal dysfunction. Apparently, this retinal dysfunction in diabetic mice is not caused by iNOS-mediated generation of nitric oxide.

Production of large quantities of nitric oxide can inhibit key enzymes in the mitochondrial electron transport chain and citric acid cycle by nitrosylation of reactive groups essential for enzyme catalytic function [37-39]. In addition, nitric oxide directly contributes to tissue damage by combining with superoxide to form peroxynitrite, a highly reactive species that produces lipid peroxidation, mitochondrial and DNA damage, and enzyme and protein inactivation. Levels of nitrotyrosine are a marker of peroxynitrite generation and reaction. iNOS is known to contribute to superoxide production [24], while deficiency of $i$ Nos results 
in less generation of superoxide anion by retina, both in diabetes (Fig. 6) and in experimental galactosaemia (another model of diabetic-like retinopathy) [40]. Besides its role in peroxynitrite formation, superoxide also has other independent effects, including oxidation of retinal proteins, potentially altering activity or turnover of the proteins and contributing to cell death $[41,42]$. In the present study, we found that the formation of nitric oxide, nitrotyrosine and superoxide was reduced in diabetic mice lacking iNos, thus probably contributing to the observed resistance of retinal capillaries from these animals to the process of degeneration in diabetes.

Nitric oxide can also contribute indirectly to cell damage. The increased production of nitric oxide induced by elevated glucose in retinal Müller cells and endothelial cells increased production of prostaglandins (via cyclooxygenase-2) and cell death [13]. Inhibition of NOS in retinal cells incubated in concentrations of glucose similar to those in diabetes prevented $\mathrm{PGE}_{2}$ production and cell death, suggesting that nitric oxide regulates cyclooxygenase activity and production of cytotoxic prostaglandins in retinal cells [13]. Findings in the present in vivo study, where retinas from diabetic $i \mathrm{Nos}^{-1-}$ mice generated less $\mathrm{PGE}_{2}$ than did retinas from diabetic WT mice, are consistent with this interpretation.

Whether or not iNOS is present in vascular cells of the retina in diabetes is controversial. In some studies, iNOS has been detected in retinal capillary endothelial cells in hyperglycaemia $[6,40]$, whereas others have not detected it $[4,5,43]$. iNOS-mediated degeneration of retinal capillaries in diabetes is probably not initiated in capillary pericytes, since high glucose has been reported to decrease iNOS expression in retinal pericytes [44]. It remains possible that the iNOS-mediated degeneration of retinal capillary cells in diabetes might be secondary to nitric oxide-mediated damage in nearby nonvascular cell types.

In diabetic rats, we found that a specific inhibitor of PARP inhibited the diabetes-induced upregulation of iNOS production in retinas (L. Zheng, T. S. Kern, unpublished data), suggesting that iNOS upregulation was secondary to PARP activation. In contrast, many investigators studying other disease models have found that iNOS-mediated generation of peroxynitrite causes PARP activation via induction of DNA strand breaks [23]. In retinas of our diabetic mice, PARP activation seemed to be less pronounced in diabetic $\mathrm{iNos}^{-1-}$ mice than in diabetic WT mice, but the results did not achieve statistical significance. In the retina in diabetes, iNOS levels apparently are regulated by PARP activation and also influences the activation of PARP.

eNOS and nNOS have also been found elevated in the retinas of diabetic rats. It has also been suggested that eNOS and nNOS levels are associated with leucostasis and/ or increased retinal vascular permeability, as well as being

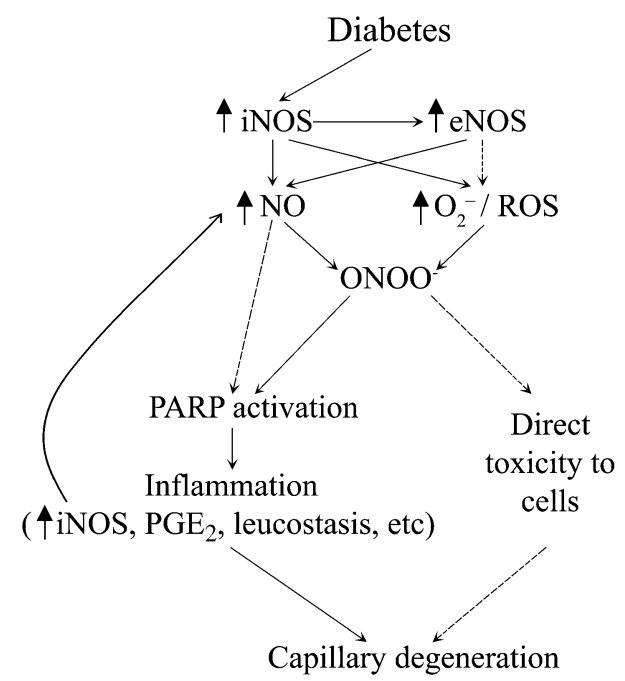

Fig. 9 Postulated role of iNOS involvement in the development of diabetic retinopathy. ROS reactive oxygen species; $O N O O$ peroxynitrite

involved in the development of diabetic retinopathy [21, $22,45,46]$. Investigation of the role of eNOS in the development of retinopathy remains difficult because of confounding by other important actions of this isoform, e.g. blood pressure regulation [47]. In this study, diabetes did not increase expression of eNOS in the retina of $i$ Nosdeficient animals, suggesting that iNOS somehow regulates eNOS level. It remains possible that the observed benefits of iNOS inhibition for the development of retinopathy might occur in part via normalisation of eNOS.

The present demonstration of a critical role of iNOS in the pathogenesis of diabetic retinopathy provides further support for the postulate that diabetic retinopathy develops via an inflammation-like process. A working hypothesis of how iNOS is involved in the development of diabetic retinopathy is summarised in Fig. 9. Inappropriate regulation of nuclear factor kappa B (NF- $\mathrm{kB})$ DNA binding has been observed in the retina in diabetes [17, 48-50], resulting in increased transcription of NF-KB-regulated gene products, including iNOS [51]. Inhibition of inflammatory pathways via inhibition of PARP [17], NF-kB [51], cyclooxygenase [52], intercellular adhesion molecule-1 [16] and now also of iNOS inhibits the diabetes-induced degeneration of retinal capillaries in experimental diabetic animals. Evidence that iNOS plays a critical role in the early stages of diabetic retinopathy points to another therapeutic target for the potential inhibition of this disease.

Acknowledgements This work was supported by grants from the Medical Research Service of the Department of Veteran Affairs and National Institutes of Health (R01EY00300) to T. S. Kern, from the Juvenile Diabetes Research Foundation and National Institutes of Health (R01EY013831) to B. A. Berkowitz, and the Diabetes Association of Greater Cleveland (fellowship grant) to L. Zheng. Technical help from R. Roberts is greatly appreciated. Histology service was provided by the Case Western Reserve University Visual Science Research Center Core Facilities (P30EY11373). 
Duality of interest The authors declare that there is no duality of interest associated with this manuscript.

\section{References}

1. Korhonen R, Lahti A, Kankaanranta H, Moilanen E (2005) Nitric oxide production and signaling in inflammation. Curr Drug Targets Inflamm Allergy 4:471-479

2. Ricciardolo FL, Nijkamp FP, Folkerts G (2006) Nitric oxide synthase (NOS) as therapeutic target for asthma and chronic obstructive pulmonary disease. Curr Drug Targets 7:721-735

3. Carmo A, Cunha-Vaz JG, Carvalho AP, Lopes MC (2000) Nitric oxide synthase activity in retinas from non-insulin-dependent diabetic Goto-Kakizaki rats: correlation with blood-retinal barrier permeability. Nitric Oxide 4:590-596

4. Du Y, Smith MA, Miller CM, Kern TS (2002) Diabetes-induced nitrative stress in the retina, and correction by aminoguanidine. J Neurochem 80:771-779

5. Abu El-Asrar AM, Desmet S, Meersschaert A, Dralands L, Missotten L, Geboes K (2001) Expression of the inducible isoform of nitric oxide synthase in the retinas of human subjects with diabetes mellitus. Am J Ophthalmol 132:551-556

6. Ellis EA, Guberski DL, Hutson B, Grant MB (2002) Time course of NADH oxidase, inducible nitric oxide synthase and peroxynitrite in diabetic retinopathy in the BBZ/WOR rat. Nitric Oxide 6:295-304

7. Misko TP, Moore WM, Kasten TP et al (1993) Selective inhibition of the inducible nitric oxide synthase by aminoguanidine. Eur J Pharmacol 233:119-125

8. Kern TS, Engerman RL (2001) Pharmacologic inhibition of diabetic retinopathy: aminoguanidine and aspirin. Diabetes 50: $1636-1642$

9. Hammes H, Martin S, Federlin K, Geisen K, Brownlee M (1991) Aminoguanidine treatment inhibits the development of experimental diabetic retinopathy. Proc Natl Acad Sci U S A 88:11555-11558

10. Kern TS, Tang J, Mizutani M et al (2000) Response of capillary cell death to aminoguanidine predicts the development of retinopathy: comparison of diabetes and galactosemia. Invest Ophthalmol Vis Sci 41:3972-3978

11. Edelstein D, Brownlee M (1992) Mechanistic studies of advanced glycosylation end product inhibition by aminoguanidine. Diabetes 41:26-29

12. Zhao W, Tilton RG, Corbett JA et al (1996) Experimental allergic encephalomyelitis in the rat is inhibited by aminoguanidine, an inhibitor of nitric oxide synthase. J Neuroimmunol 64:123-133

13. Du Y, Sarthy V, Kern T (2004) Interaction between NO and COX pathways in retinal cells exposed to elevated glucose and retina of diabetic rats. Am J Physiol 287:R735-R741

14. Kowluru RA, Engerman RL, Kern TS (2000) Abnormalities of retinal metabolism in diabetes or experimental galactosemia VIII. Prevention by aminoguanidine. Curr Eye Res 21:814-819

15. Du Y, Miller CM, Kern TS (2003) Hyperglycemia increases mitochondrial superoxide in retina and retinal cells. Free Radic Biol Med 35:1491-1499

16. Joussen AM, Poulaki V, Le ML et al (2004) A central role for inflammation in the pathogenesis of diabetic retinopathy. FASEB J 18:1450-1452

17. Zheng L, Szabo C, Kern TS (2004) Poly(ADP-ribose) polymerase is involved in the development of diabetic retinopathy via regulation of nuclear factor-kappaB. Diabetes 53:2960-2967

18. Ball SL, Powers PA, Shin HS, Morgans CW, Peachey NS, Gregg RG (2002) Role of the beta(2) subunit of voltage-dependent calcium channels in the retinal outer plexiform layer. Invest Ophthalmol Vis Sci 43:1595-1603

19. Hancock HA, Kraft TW (2004) Oscillatory potential analysis and ERGs of normal and diabetic rats. Invest Ophthalmol Vis Sci 45:1002-1008

20. Kowluru RA (2002) Retinal metabolic abnormalities in diabetic mouse: comparison with diabetic rat. Curr Eye Res 24:123-128

21. Joussen AM, Poulaki V, Qin W et al (2002) Retinal vascular endothelial growth factor induces intercellular adhesion molecule1 and endothelial nitric oxide synthase expression and initiates early diabetic retinal leukocyte adhesion in vivo. Am J Pathol 160:501-509

22. Joussen AM, Poulaki V, Mitsiades N et al (2002) Nonsteroidal anti-inflammatory drugs prevent early diabetic retinopathy via TNF-alpha suppression. FASEB J 16:438-440

23. Virag L, Szabo C (2002) The therapeutic potential of poly(ADPribose) polymerase inhibitors. Pharmacol Rev 54:375-429

24. Xia Y, Zweier JL (1997) Superoxide and peroxynitrite generation from inducible nitric oxide synthase in macrophages. Proc Natl Acad Sci U S A 94:6954-6958

25. Joussen AM, Murata T, Tsujikawa A, Kirchhof B, Bursell SE, Adamis AP (2001) Leukocyte-mediated endothelial cell injury and death in the diabetic retina. Am J Pathol 158:147-152

26. Berkowitz BA, Luan H, Gupta RR et al (2004) Regulation of the early subnormal retinal oxygenation response in experimental diabetes by inducible nitric oxide synthase. Diabetes 53:173-178

27. Berkowitz BA, Roberts R, Luan H et al (2005) Drug intervention can correct subnormal retinal oxygenation response in experimental diabetic retinopathy. Invest Ophthalmol Vis Sci 46:2954-2960

28. Barber AJ, Lieth E, Khin SA, Antonetti DA, Buchanan AG, Gardner TW (1998) Neural apoptosis in the retina during experimental and human diabetes. Early onset and effect of insulin. J Clin Invest 102:783-791

29. VanGuilder HD, Ellis RW, Freeman WM, Barber AJ (2006) Streptozotocin-diabetes decreases synaptic protein expression in rat retina. Invest Ophthalmol Vis Sci 47:1733 (ARVO E-Abstract)

30. Hammes HP, Federoff HJ, Brownlee M (1995) Nerve growth factor prevents both neuroretinal programmed cell death and capillary pathology in experimental diabetes. Mol Med 1:527-534

31. Lieth E, Gardner TW, Barber AJ, Antonetti DA, Penn State Retina Research Group (2000) Retinal neurodegeneration: early pathology in diabetes. Clin Experiment Ophthalmol 28:3-8

32. Asnaghi V, Gerhardinger $\mathrm{C}$, Hoehn $\mathrm{T}$, Adeboje A, Lorenzi $\mathrm{M}$ (2003) A role for the polyol pathway in the early neuroretinal apoptosis and glial changes induced by diabetes in the rat. Diabetes 52:506-511

33. Feit-Leichman RA, Kinouchi R, Takeda M et al (2005) Vascular damage in a mouse model of diabetic retinopathy: relation to neuronal and glial changes. Invest Ophthalmol Vis Sci 46:4281-4287

34. Agardh E, Bruun A, Agardh CD (2001) Retinal glial cell immunoreactivity and neuronal cell changes in rats with STZinduced diabetes. Curr Eye Res 23:276-284

35. Martin PM, Roon P, Van Ells TK, Ganapathy V, Smith SB (2004) Death of retinal neurons in streptozotocin-induced diabetic mice. Invest Ophthalmol Vis Sci 45:3330-3336

36. Barber AJ, Antonetti DA, Kern TS et al (2005) The Ins2Akita mouse as a model of early retinal complications in diabetes. Invest Ophthalmol Vis Sci 46:2210-2218

37. Beckman JS, Koppenol WH (1996) Nitric oxide, superoxide, and peroxynitrite: the good, the bad, and ugly. Am J Physiol 271: C1424-C1437

38. Burney S, Caulfield JL, Niles JC, Wishnok JS, Tannenbaum SR (1999) The chemistry of DNA damage from nitric oxide and peroxynitrite. Mutat Res 424:37-49

39. Szabo C, Ohshima H (1997) DNA damage induced by peroxynitrite: subsequent biological effects. Nitric Oxide 1:373-385 
40. Ellis EA, Sengupta N, Caballero S, Guthrie SM, Mames RN, Grant MB (2005) Nitric oxide synthases modulate progenitor and resident endothelial cell behavior in galactosemia. Antioxid Redox Signal 7:1413-1422

41. Sugawara T, Lewen A, Gasche Y, Yu F, Chan PH (2002) Overexpression of SOD1 protects vulnerable motor neurons after spinal cord injury by attenuating mitochondrial cytochrome $c$ release. FASEB J 16:1997-1999

42. Sugawara T, Noshita N, Lewen A et al (2002) Overexpression of copper/zinc superoxide dismutase in transgenic rats protects vulnerable neurons against ischemic damage by blocking the mitochondrial pathway of caspase activation. J Neurosci 22:209 217

43. Abu El-Asrar AM, Meersschaert A, Dralands L, Missotten L, Geboes K (2004) Inducible nitric oxide synthase and vascular endothelial growth factor are colocalized in the retinas of human subjects with diabetes. Eye 18:306-313

44. Kim J, Oh YS, Shinn SH (2005) Troglitazone reverses the inhibition of nitric oxide production by high glucose in cultured bovine retinal pericytes. Exp Eye Res 81:65-70

45. Park JW, Park SJ, Park SH et al (2006) Up-regulated expression of neuronal nitric oxide synthase in experimental diabetic retina. Neurobiol Dis 21:43-49
46. Takeda M, Mori F, Yoshida A et al (2001) Constitutive nitric oxide synthase is associated with retinal vascular permeability in early diabetic rats. Diabetologia 44:1043-1050

47. Huang PL, Huang Z, Mashimo H et al (1995) Hypertension in mice lacking the gene for endothelial nitric oxide synthase. Nature 377:239-242

48. Romeo G, Liu WH, Asnaghi V, Kern TS, Lorenzi M (2002) Activation of nuclear factor-kappaB induced by diabetes and high glucose regulates a proapoptotic program in retinal pericytes. Diabetes 51:2241-2248

49. Kowluru RA, Koppolu P, Chakrabarti S, Chen S (2003) Diabetesinduced activation of nuclear transcriptional factor in the retina, and its inhibition by antioxidants. Free Radic Res 37:1169-1180

50. Poulaki V, Joussen AM, Mitsiades N, Mitsiades CS, Iliaki EF, Adamis AP (2004) Insulin-like growth factor-I plays a pathogenetic role in diabetic retinopathy. Am J Pathol 165:457-469

51. Zheng L, Howell SJ, Hatala DA, Huang K, Kern TS (2007) Salicylate-based anti-inflammatory drugs inhibit the early lesion of diabetic retinopathy. Diabetes 56:337-345

52. Kern TS, Miller CM, Du Y et al (2007) Topical administration of nepafenac inhibits diabetes-induced retinal microvascular disease and underlying abnormalities of retinal metabolism and physiology. Diabetes 56:373-379 